Fatty acid composition and prostaglandin content of ... (Muhammad Ikbal Illijas)

\title{
FATTY ACID COMPOSITION AND PROSTAGLANDIN CONTENT OF THE RED SEAWEED Gracilaria sp. FROM INDONESIA
}

\author{
Muhammad Ikbal Illijas*\#, Arifuddin*), Luqman Saleh*), and Yutaka Itabashi*) \\ *) Department of Aquaculture, Pangkep State Polytechnic of Agriculture, Indonesia \\ ${ }^{* *)}$ Graduate School of Fisheries Sciences, Hokkaido University, Japan
}

(Received 17 October 2011 ; Accepted 12 April 2012)

\begin{abstract}
High content of polyunsaturated fatty acids (PUFAs) such as arachidonic and eicosapentaenoic acids are typical for the red alga. Analysis of fatty acid composition and prostaglandin content was conducted in the red alga Gracilaria sp. from Indonesia. Total lipid of the alga was extracted with $\mathrm{CHCl}_{3}-\mathrm{MeOH}(2: 1, \mathrm{v} / \mathrm{v})$. Analysis of the fatty acids composition was performed on gas chromatography (GC) equipped with omega wax column ( $30 \mathrm{~m} \times 0,32 \mathrm{~mm}$ i.d., Supelco, PA, USA) and analysis of prostaglandins were carried out by HPLC on ODS column (Mightysil RP-18 GP, $250 \mathrm{~mm} \times 4.6 \mathrm{~mm}, 5 \mu \mathrm{m}$ ). The content of fatty acids high for were palmitic acid $(50 \%$ and arachidonic acid $\left(26.9 \%\right.$, whereas prostaglandin $E_{2}$ was identified and found lower concentration $(44.2$ $\mu \mathrm{g} / \mathrm{gram}$ total lipid).
\end{abstract}

KEYWORDS: fatty acids, prostaglandins, Gracilaria, seaweed

\section{INTRODUCTION}

Red algae are well recognized as sources of polyunsaturated fatty acids (PUFAs) with 20 carbon atoms, mainly arachidonic acid (20:4n6) and eicosapentaenoic acid (20:5n-3). These PUFAs have unique biological activities and are the precursors in biosynthesis of prostaglandins, leucotrienes and other eicosaenoids, which are important to the maintenance of normal mammalian physiology (Gerwick et al., 1993; Gerwick \& Bernet, 1993). The majority of the red algal species are rich in 20:5n- 3 or contain about equal amounts of 20:5n- 3 and 20:4n6. However, G. verrucosa (G. vermiculophyla) contains higher of 20:4n- 6 than 20:5n- 3 (Pohl et al., 1968; Takagi et al., 1985; Araki et al., 1986; Khotimchenko et al., 1991; Dawes et al., 1993), Khotimchenko \& Levchenko, 1997).
The red alga G. verrucosa, which is intensively cultured in coastal areas of shrimp and fish shrimp ponds in Indonesia, has luck of information in detail regarding its lipid bioactive contents. Although there were some species of Gracilaria have been published in detail about their lipid bioactive contents those collected from Japanese Waters, such as G. vermiculophylla (Itabashi et al., 2006), G. gigas (Hsu et al., 2007), and G. asiatica (Sajiki, 1996). Another species is G. chilensis (Lion et al., 2006) collected from Chile, which contained different lipids bioactive from other Gracilaria species.

The aim of study was to evaluate fatty acids and eicosanoid composition of Indonesian red alga $\mathrm{G}$. verrucosa.

\# Corresponding author. Department of Aquaculture, Pangkep State Polytechnic of Agriculture Jl. Poros Makassar, Pane Km 82, Pangkajene, Sulawesi Selatan, Indonesia. Tel.: 081343956621 E-mail address: muhammadikbali@yahoo.com 


\section{MATERIALS AND METHODS}

\section{Seaweed}

The red seaweed Gracilaria sp. was collected from shrimp ponds located in Bone District, South Sulawesi. A part of the alga was extracted at Department of Aquaculture, Pangkep State Polytechnic of Agriculture. Another part of the alga was freezed for further extraction at Bioanalytical Chemistry Laboratory, Hokkaido University, Japan

\section{Lipid Extraction}

Each Gracilaria sp. sample was cut into pieces (3- $5 \mathrm{~mm}$ ) and homogenized for $5 \mathrm{~min}$. at room temperature. Lipids was extracted by soaking the homogenate overnight in $\mathrm{CHCl}_{3} /$ $\mathrm{MeOH} / \mathrm{H}_{2} \mathrm{O}$ (2:1:0.8 by vol.). After filtration, the solvent will removed at $25^{\circ} \mathrm{C}$ under reduced pressure using a rotary evaporator, and then the residual lipids was made up to a known concentration with $\mathrm{CHCl}_{3} / \mathrm{MeOH}(2: 1, \mathrm{v} / \mathrm{v})$ and stored at $-30^{\circ} \mathrm{C}$ until use.

\section{Analysis of FFA Composition}

FFAs were converted to methyl esters by heating at $95^{\circ} \mathrm{C}$ for $1 \mathrm{~h}$ in $5 \% \mathrm{HCl} / \mathrm{MeOH}$ (Christie, 2003). Analysis of the fatty acid methyl esters was carried out using a Shimadzu GC-14A gas chromatograph (Shimadzu) equipped with an Omegawax 320 column (30 $\mathrm{m} \times 0.32 \mathrm{~mm}$ i.d., Supelco, PA, USA). Helium was used as the carrier gas at a constant flow rate of $1 \mathrm{~mL} / \mathrm{min}$. The split ratio was 1:50. The column temperature was maintained at $160^{\circ} \mathrm{C}$ for $17 \mathrm{~min}$, then elevated to $230^{\circ} \mathrm{C}$ at a ramp rate of $5^{\circ} \mathrm{C} / \mathrm{min}$. The final temperature was kept for $30 \mathrm{~min}$. The injector and flame- ionization detector (FID) temperatures were set at $240^{\circ} \mathrm{C}$. Peaks were monitored on a Chromatopac CR6A (Shimadzu) and identified by comparing retention data of the known fatty acids from some marine organisms including seaweeds (Takagi et al., 1985; Takagi et al., 1986).

\section{Identification of Prostaglandins}

For identification of eicosanoid compounds, LC/ MS was used. Total lipids was subjected to LC/MS equipped with a Mightysil column, RP-18 GP (250 mm x $4.6 \mathrm{~mm}, 5 \mu \mathrm{m})$. Identification of eicosanoid compounds was conducted by comparing their mass spectra with those of authentic standard. For complete identification of the eicosanoid compounds, co-chromatography using authentic compounds was employed.

\section{Determination of Prostaglandin Contents}

The alga was finely sliced and placed in $100 \mathrm{~mL}$ - bottle. To which $30 \mathrm{~mL}$ of ethyl acetate and $150 \mu \mathrm{L}$ of $1 \mathrm{M} \mathrm{HCl}$ in methanol was added. The mixtures were shaken for $5 \mathrm{~min}$. and then centrifuged at $2,500 \mathrm{rpm}$ for $5 \mathrm{~min}$. at $20^{\circ} \mathrm{C}$. The supernatants were pipetted and evaporated under reduced pressure using a rotary evaporator at $25^{\circ} \mathrm{C}$. This procedure was repeated once more. The residue was dissolved in $200 \mu \mathrm{L}$ of methanol as test solution. For determination of PGs, the test solution $(5 \mu \mathrm{L})$ was subjected to HPLC (Hitachi Ltd, Tokyo, Japan) on a Mightysil column, RP- 18 GP ( $250 \mathrm{~mm}$ x 4.6 $\mathrm{mm}, 5 \mu \mathrm{m})$. Determination of PGs was carried out by comparing the peak of PGs extracted from samples and authentic standards of PG. The contents of PGs in the samples was calculated from standard curve of the PG standards.

\section{HPLC and LC Conditions}

HPLC was performed at $40^{\circ} \mathrm{C}$ using a gradient elution from acetonitrile/ water (40:60, $\mathrm{v} / \mathrm{v}$ ) containing $0.02 \%$ acetic acid (solvent $\mathrm{A}$ ) to $100 \%$ acetonitrile (solvent B). The mobile phase system is as follows: $0-20 \mathrm{~min}$. (solvent A), 20- 60 min. (gradient of solvent $A$ and $B$ ) and $60-80 \mathrm{~min}$. (solvent $B$ ). The flow rate is $0.5 \mathrm{~mL}$ min. The PG peaks were monitored by a diode array detector (Model L- 7455 LaChrom, Hitachi Ltd, Tokyo, Japan) set at $196 \mathrm{~nm}$.

\section{RESULTS AND DISCUSSION}

\section{Fatty Acid Composition}

Analysis of fatty acid compositions of the red alga by GC was shown in Table 1 . The result showed that the dominant fatty acids were palmitic acid (C16:0, 50\%) and arachidonic acid (C20:4n- 6, 29.6\%). There were significant amounts of the fatty acids, namely stearic acid (C14:0) dan oleic acid (C18:1n-9).

C16:0 is saturated fatty acid, which is abundantly found in many kind of seaweed (Stefanov et al., 1988; Aknin et al., 1990; Khotimchenko, 1998). Whereas, the polyunsaturated acid, C20:4n- 6 is a typical fatty acid for the red algae (Khotimchenko et al., 1990; Araki et al., 1990; Illijas et al., 2009). This fatty acid is synthesized from hydrolysis of lipid membrane, glycoglycerolipids, such as 
Fatty acid composition and prostaglandin content of ... (Muhammad Ikbal Illijas)

Table 1. Fatty acid composition of the red alga Gracilaria sp.

\begin{tabular}{|c|c|}
\hline Fatty acid & Composition \\
\hline $14: 0$ & $3.0 \pm 0.3$ \\
\hline iso $15: 0$ & $0.2 \pm 0.0$ \\
\hline anteiso 15:0 & $0.1 \pm 0.1$ \\
\hline $15: 0$ & $05 \pm 0.2$ \\
\hline $15: 1$ & nd \\
\hline iso $16: 0$ & $0.1 \pm 0.0$ \\
\hline anteiso 16:0 & $0.1 \pm 0.0$ \\
\hline $16: 0$ & $50.0 \pm 4.4$ \\
\hline iso $17: 0$ & $0.4 \pm 0.0$ \\
\hline $17: 0$ & $0.2 \pm 0.1$ \\
\hline $18: 0$ & $1.1 \pm 0.3$ \\
\hline $20: 0$ & $0.1 \pm 0.0$ \\
\hline $22: 0$ & $0.2 \pm 0.0$ \\
\hline $24: 0$ & nd \\
\hline Saturates & 56.0 \\
\hline $14: 1 n-9$ & nd \\
\hline $16: 1 n-7.9$ & $1.8 \pm 0.2$ \\
\hline $16: 1 n-5$ & nd \\
\hline $18: 1 n-9$ & $3.3 \pm 0.4$ \\
\hline $18: 1 n-7$ & $1.3 \pm 0.1$ \\
\hline $18: 1 n-5$ & nd \\
\hline $24: 1 n-9$ & nd \\
\hline Monoenes & 6.4 \\
\hline $16: 2 n-4$ & nd \\
\hline $16: 3 n-4$ & $0.2 \pm 0.2$ \\
\hline $18: 2 n-6$ & $0.7 \pm 0.0$ \\
\hline $18: 3 n-6$ & $0.4 \pm 0.1$ \\
\hline $18: 3 n-3$ & $0.1 \pm 0.0$ \\
\hline $18: 4 n-3$ & $0.2 \pm 0.3$ \\
\hline $20: 2 n-6$ & $0.2 \pm 0.1$ \\
\hline $20: 3 n-6$ & $2.4 \pm 0.1$ \\
\hline $20: 4 n-6$ & $29.6 \pm 2.6$ \\
\hline $20: 3 n-3$ & nd \\
\hline $20: 4 n-3$ & nd \\
\hline $20: 5 n-3$ & $0.1 \pm 0.0$ \\
\hline $22: 6 n-3$ & nd \\
\hline Polyenes & 34.0 \\
\hline Others & $3.6 \pm 0.9$ \\
\hline
\end{tabular}

nd : not detected

$\operatorname{tr}:$ trace $(<0.1)$ monogalactosyldiasylglyserol (MGDG), digalactosyldiasylglyserol (DGDG) and sulfoquinovosyldiasylglyserol (SQDG) catalized by glycerolip acyl-hydrolase (Figure 1, Illijas et al., 2008). Function of the arachidonic acid is a precursor for biosynthesis of prostaglandins and other eicosanoic compounds in the red algae (Hsu et al., 2007; Illijas, 2008).

\section{Prostaglandin}

In the HPLC chromatograms (Figure 2), one of peaks was identified as prostaglandin $E_{2}$ $\left(\mathrm{PGE}_{2}\right)$. The identification was conducted by comparing the chromatograms with HPLC chromatogram of prostaglandin standards (Figure 3).

This prostaglandin is also found abundantly in many species of the red algae, such as $\mathrm{G}$. gigas (Hsu et al., 2007), G. asiatica (Sajiki et al., 1998), G. vermiculophylla (Illijas, 2008).

Biosynthesis pathway of prostaglandin in seaweed is still unclear. However, it was found that prostaglandin is formed from oxidation of arachidonic acid, which is likely involve cyclooxygenase as catalyst, because prostaglandin formation decreased as addition of aspirin, an anti cyclooxygenase compound, was conducted to reaction mixtures of $G$. vermiculophylla extract and free arachidonic acid (Figure 4) (Illijas, 2008).

Prostaglandin function is also still unclear in the seaweed. However, several result of researches showed that formation of prostaglandins occurred when the seaweed was physically treated (Nakaj ima et al., 1998) so that the prostaglandins also known as secondary metabolites. The prostaglandins have also been found to be produced along with other eicosanoid compounds when the red alga Chondrus crispus was incubated with pathogen extract (Bouarab et al., 2004; Gaquerel et al., 2007). In mammals and human, prostaglandins play an important role as hormone, which control several kinds of metabolism (Samuelsson, 1975).

\section{CONCLUSION}

Arachidonic acid, the dominant polyunsaturated fatty acid found in the seaweed, is precursor of synthesis of prostaglandin $E_{2}$, the only eicosanoic compound could be identified in this study. 
Indonesian Aquaculture Journal Vol.7 No.1, 2012

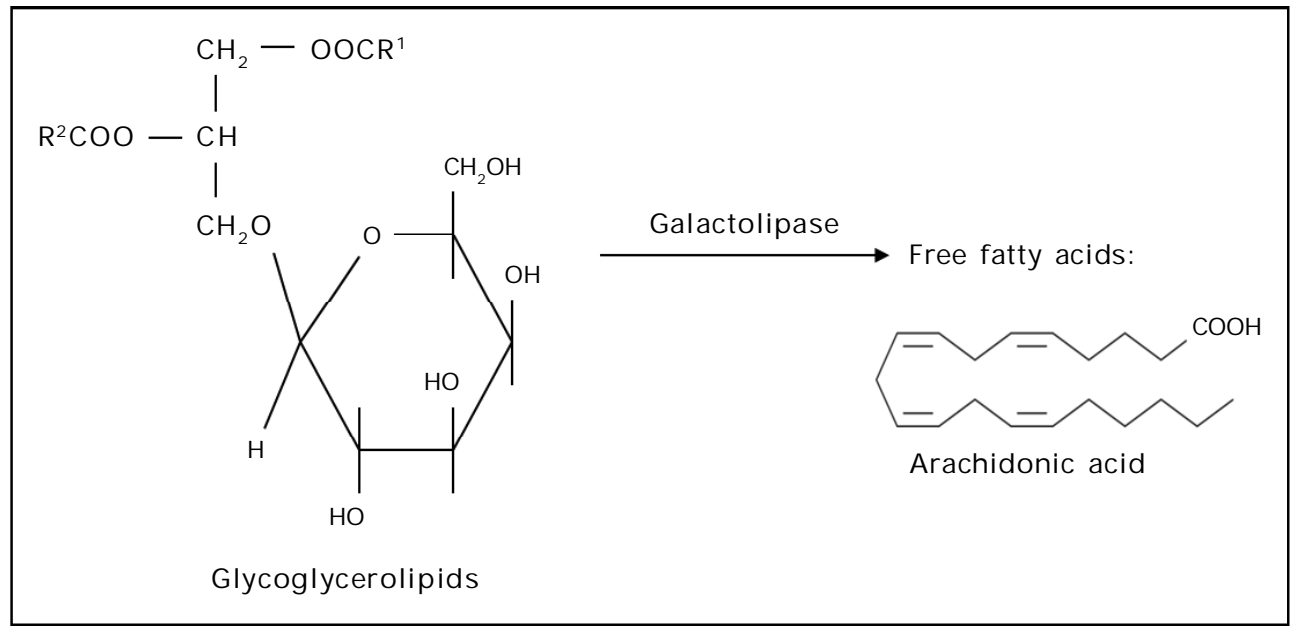

Figure 1. Biosynthesis pathway of arachidonic acid in the red alga G. vermiculophylla (IIlijas et al., 2008)
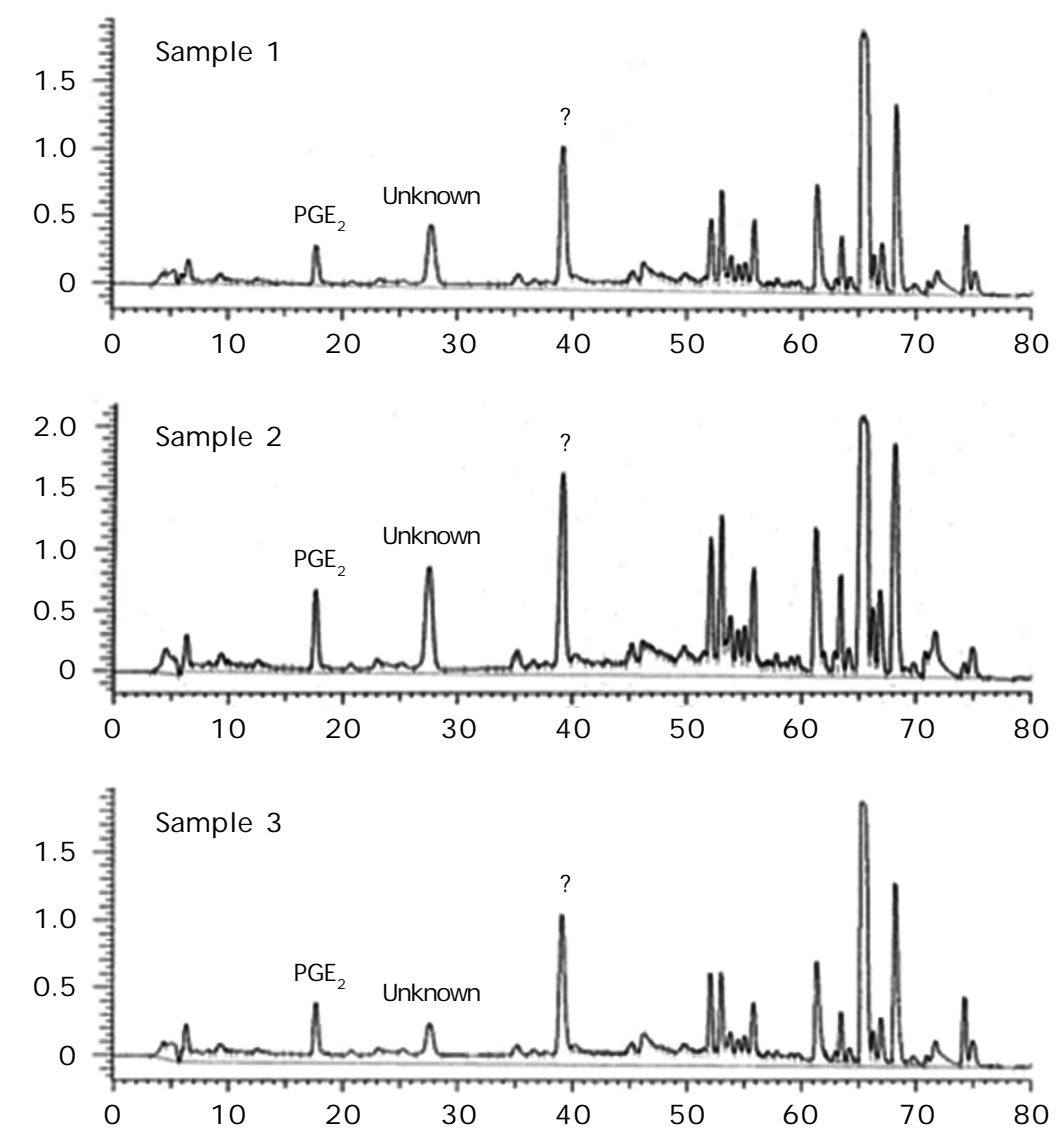

Figure 2. HPLC chromatograms of the red alga Gracilaria sp. extracts $\left(\mathrm{CHCl}_{3}-\mathrm{MeOH}\right.$ extracts) 
Fatty acid composition and prostaglandin content of ... (Muhammad Ikbal Illijas)

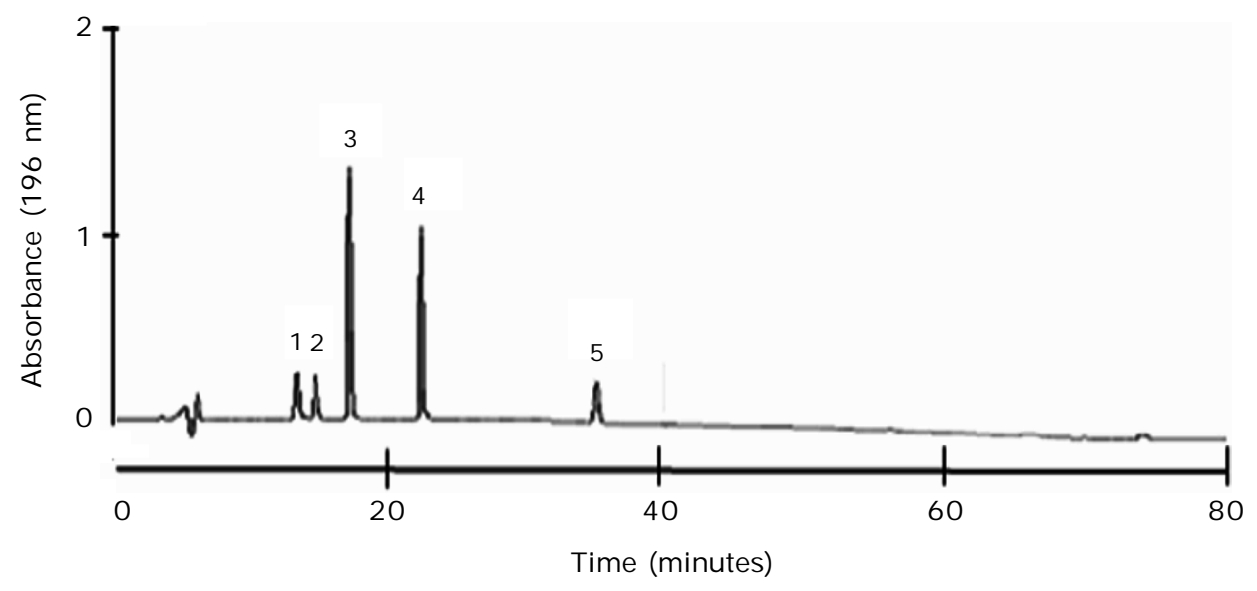

Figure 3. HPLC chromatogram of prostaglandin standards. Peak 1: PGE ${ }_{3}$; Peak 2: PGF $2 \alpha$; Peak 3: $\mathrm{PGE}_{2}$; Peak 4: 15- keto- $\mathrm{PGE}_{2}$; Peak 5: PGA

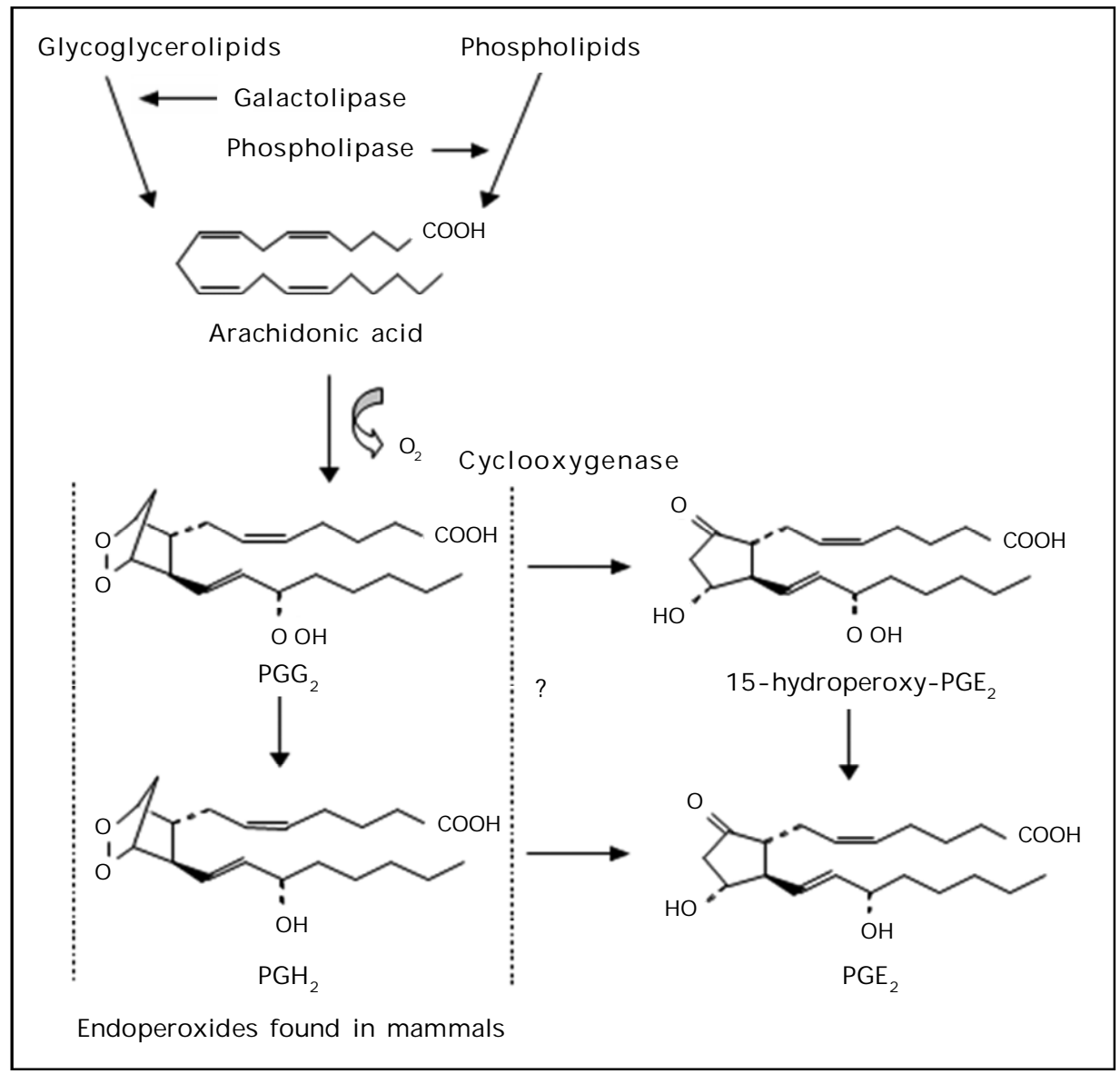

Figure 4. Proposed biosynthesis pathway of prostaglandin in the red alga G. vermiculophylla (Illijas, 2008) 


\section{ACKNOWLEDGMENTS}

This study was part funded by IndonesianManagement of Higher Education for relevance and efficiency (I-MHERE) Project B.I Batch III Directorate General of Higher Educatioan and World Bank, awarded to Pangkep State Polytechnic of Agriculture, South Sulawesi, Indonesia.

\section{REFERENCES}

Aknin, M., Miralles, J., \& Kornprobst, J- M. 1990. Sterol and fatty acid distribution in red algae from the Senegalase coast. Comp. Biochem. Physiol., 96B: 559- 563.

Araki, S., Sakurai, T., Oohusa, T., Kayama, M., \& Nisizawa, K. 1990. Content of arachidonic and eicosapentaenoic acids in polar lipids from Gracilaria (Gracilariales, Rhodophyta). Hydrobilogia, 204/205: 513- 519.

Bouarab, K., Adas, F., Gaquerel, E., Kloareg, B., Salaun, J- P., \& Potin, P. 2004. The innate immunity of a marine red alga involves oxylipin from both the eicosanoid and octadecanoid pathways. Plant Physiology, 135: 1,838- 1,848.

Christie, W.W. 2003. Preparation of derivatives of fatty acids. In Lipid analysis, third edition; The Oily Press: Bridgwater, England, p. 205- 224.

Gaquerel, E., Herve, C., Labriere, C., Boyen, C., Potin, P., \& Salaun, J- P. 2007. Evidence for oxylipin synthesis and induction of a new polyunsaturated fatty acid hydroxylase activity in Chondrus crispus in response to methyljasmonate. Biochemica et Biophysica Acta, 1771: 565- 575.

Hsu, B-Y., Tsao, C-Y., Chiou, T- C., Hwang, P- A., \& Hwang, D- F. 2007. HPLC determination for prostaglandins from seaweed Gracilaria gigas. Food Control, 18: 639-645.
Illijas, M.I., Nakamura, \&Terasaki, M. 2008. Purification and characterization of glicerolipid acyl- hydrolase from the red alga Gracilaria vermiculophylla. Fisheries Science, 74: 670676.

Illijas, M.I., Rimber, R.I., Yasui, T., \& Itabashi, Y. 2009. Lipid class dan fatty acid composition of a little- known and rarely collected alga Exophyllum wentii Weber-van Bosse from Bali Island, Indonesia. Olei Science, 58(3): 103- 110.

Illijas, M.I. 2008. Lipid and prostaglandin in the red alga, Gracilaria vermiculophylla. Thesis, Graduate School of Fisheries Sciences, Hokkaido University, Japan.

Khotimchenko, S.V. 1998. Fatty acids of brown algae from Russian far east. Phytochemistry, 49: 2,363- 2,369.

Lion, U., Wiesemier, T., Weinberger, F., Beltran, J., Flores, V., Faugeron, S., Correa, J., \& Pohnert, G. 2006. Phospholipases and galactolipases trigger oxylipin- mediated wound-activated defence in the red alga Gracilaria chilensis against epiphytes. Chem. Bio. Chem., 7: 457-462.

Sajiki, J. \& Kakimi, H. 1998. Identification of eicosanoids in the red algae, Gracilaria asiatica, using high-performance liquid chromatography and electrospray ionization mass spectrometry. Journal of Chromatography A, 795: 227- 237.

Samuelsson, B., Granstr6m, E., Green, K., Hamberg, M., \&Hammarstrom, S. 1975. Prostaglandins. Annual Reviews.

Stefanov, K., Konaklieva, M., Brechany, E.Y., \& Christie, W.W. 1988. Fatty acid composition of some algae from the black sea. Phytochemistry, 27: 3,495- 3,497.

Takagi, T., Asahi, M., \& Itabashi, Y. 1985. Fatty acid composition of twelve algae from Japanese waters. Yukagaku, 34: 1,008-1,012. 